\title{
Preventive effect of gomisin J from Schisandra chinensis on angiotensin II-induced hypertension via an increased nitric oxide bioavailability
}

\author{
Byeong Hyeok Ye ${ }^{1,3}$, Seung Jin Lee ${ }^{1,3}$, Young Whan $\mathrm{Choi}^{2}$, So Youn Park ${ }^{1}$ and Chi Dae Kim ${ }^{1}$
}

Gomisin J (GJ) is a small molecular weight lignan found in Schisandra chinensis and has been demonstrated to have vasodilatory activity. In this study, the authors investigated the effect of GJ on blood pressure (BP) in angiotensin II (Ang II)induced hypertensive mice. In addition, we determined the relative potencies of gomisin A (GA) and GJ with respect to vasodilatory activity and antihypertensive effects. C57/BL6 mice infused s.c. with Ang II ( $2 \mathrm{\mu g} \mathrm{kg}^{-1} \mathrm{~min}^{-1}$ for 2 weeks) showed an increase in BP and a decrease in plasma nitric oxide (NO) metabolites. In the thoracic aortas of Ang II-induced hypertensive mice, a decrease in vascular NO was accompanied by an increase in reactive oxygen species (ROS) production. Furthermore, these alterations in BP, plasma concentrations of NO metabolites and in the vascular productions of NO and ROS in Ang II-treated mice were reversed by the co-administration of GJ $\left(1\right.$ and $\left.3 \mu \mathrm{gg}^{-1} \mathrm{~min}^{-1}\right)$. In in vitro studies, Ang II decreased the cellular concentration of NO, which was accompanied by a reduction in phosphorylated endothelial nitric oxide synthase (eNOS) and an increase in ROS production. These eNOS phosphorylation and ROS production changes in Ang II-treated cells were also reversed by GJ pretreatment $\left(0-3 \mu \mathrm{g} \mathrm{ml}^{-1}\right)$. Interestingly, the vasodilatory and antihypertensive effects of GJ were more prominent than those of GA. Collectively, an increase in BP in mice treated with Ang II was markedly attenuated by GJ, which was attributed to the preservations of vascular NO bioavailability and eNOS function, and to the inhibition of ROS production in Ang II-induced hypertensive mice.

Hypertension Research (2015) 38, 169-177; doi:10.1038/hr.2014.162; published online 27 November 2014

Keywords: angiotensin II; blood pressure; gomisin J; nitric oxide; ROS

\section{INTRODUCTION}

Hypertension is a major cardiovascular risk factor, ${ }^{1-3}$ and dysfunctional endothelium (ED) is recognized as an independent factor of an increase in arterial blood pressure (BP), ${ }^{4}$ which in addition to being the most common cardiovascular disease is an independent, though modifiable, risk factor of cardiovascular and cerebrovascular diseases. ${ }^{1,5}$ It is well known that the impairment in endothelial nitric oxide synthase (eNOS) activity has an important role in the pathogenesis of endothelial cell dysfunction. Previous studies indicate that eNOS activity is upregulated by post-translational modifications, such as Akt-induced phosphorylation, ${ }^{6,7}$ and thus, it is considered that a decline in nitric oxide (NO) bioavailability may be caused by alterations in cellular signaling involved in eNOS activation, as well as by accelerated NO degradation by reactive oxygen species (ROS). ${ }^{8}$

An increasing evidence suggests novel roles for angiotensin II (Ang II) in the regulation of balance between $\mathrm{NO}$ and ROS in the vasculature. ${ }^{9,10}$ Ang II activates $\mathrm{NAD}(\mathrm{P}) \mathrm{H}$ oxidase and induces ROS generation in vascular smooth muscle cells (VSMCs), endothelial cells and intact arteries. ${ }^{11}$ Furthermore, NADPH oxidase-derived ROS have a role in vascular pathology and in the maintenance of normal physiological vascular function. ${ }^{12}$ Moreover, strict cross-talk between Ang II and NADPH oxidase has been confirmed by in vivo studies. ${ }^{11}$ Indeed, many of the consequences of Ang II exposure, including hypertension and vascular remodeling, are reportedly related to the production of ROS. ${ }^{13,14}$ In Ang II-induced hypertensive mice, voltagedependent calcium channels in endothelial cells contribute to ROS production and endothelial dysfunction. ${ }^{15}$

Schisandra chinensis (SC) fruits contain a variety of pharmacologically active lignans that possess a dibenzocyclooctadiene skeleton and these include gomisin A (GA), gomisin J (GJ) and gomisin N. ${ }^{16,17}$ Traditionally, SC has been used as an antioxidant, an antitussive, an anti-ageing agent and an astringent and for the treatment of cardiovascular symptoms in Korea, China and Japan. ${ }^{18-20}$ Previous studies have shown that GJ protects against hydrogen peroxide-

\footnotetext{
${ }^{1}$ Department of Pharmacology, School of Medicine and MRC for Ischemic Tissue Regeneration, Pusan National University, Yangsan, Gyeongnam, Republic of Korea and ${ }^{2}$ College of Natural Resources \& Life Sciences, Pusan National University, Yangsan, Gyeongnam, Republic of Korea

3These authors contributed equally to this work.

Correspondence: Professor CD Kim, Department of Pharmacology, School of Medicine and MRC for Ischemic Tissue Regeneration, Pusan National University, Yangsan, Gyeongnam 626-870, Republic of Korea.

E-mail: chidkim@pusan.ac.kr
}

Received 31 March 2014; revised 4 September 2014; accepted 23 October 2014; published online 27 November 2014 
induced cell death ${ }^{21}$ and LPS-induced inflammatory reactions. ${ }^{22}$ However, our knowledge of the pharmacological mechanism responsible for the effects of GJ on the cardiovascular system is limited. Recently, we demonstrated that GJ isolated from SC induced vasorelaxation, ${ }^{23}$ which suggested that GJ might prevent increases in arterial BP.

In the present study, we evaluated the effect of chronic GJ treatment in Ang II-induced hypertensive mice with respect to its efficacy and biochemical mechanisms. In addition, we determined the relative potencies of GA and GJ with respect to vasodilatory activity and antihypertensive effects in Ang II-induced hypertensive mice.

\section{METHODS}

\section{Plant collection and extraction of GJ and GA}

SC fruits were collected in September 2005 from Mungyeong, Republic of Korea. A voucher specimen (accession number SC-PDRL-1) has been deposited in the Herbarium of Pusan National University. SC was identified by one of the authors (Young Whan Choi).

The dried fruits of SC were ground to a fine powder and extracted with $\mathrm{n}$-hexane. The suspension obtained was filtered, evaporated and lyophilized to obtain the hexane extract. This extract was chromatographed on a silica gel column (40 m, J.T. Baker, NJ, USA) using a ethyl acetate in hexane step gradient. Fraction 26 was separated on a silica gel column using $1 \%$ acetone in $\mathrm{CH}_{2} \mathrm{Cl}_{2}$ to obtain 26IA-26IT. Fraction 26IJ was re-separated on a silica gel column using $1 \%$ acetone in $\mathrm{CH}_{2} \mathrm{Cl}_{2}$ to give GJ. The solid form of GJ was dissolved in $100 \%$ dimethyl sulfoxide to produce stock solutions of concentration $100 \mathrm{mgl}^{-1}$ and these were subsequently diluted in media for experiments. GA was prepared as previously described. ${ }^{24}$

\section{Cell culture}

A mouse aorta was dissected, cut into $1-2 \mathrm{~mm}^{2}$ segments and placed as explants in cell culture dishes containing Dulbecco's modified Eagle's medium (DMEM) (Gibco BRL, Grand Island, NY, USA) plus 10\% fetal bovine serum. VSMC purity was determined by staining with smooth muscle-specific actin monoclonal antibodies (Sigma-Aldrich, St Louis, MO, USA). YPEN-1 was obtained from ATCC (Manassas, VA, USA). Cells were cultured in DMEM containing $5 \%$ fetal bovine serum.

\section{Animals and experimental design}

All animal procedures were conducted in accordance with the guidelines issued by the Pusan National University Animal Care and Use Committee. Male C57BL/6 mice (20-25 g, 8 weeks of age) were implanted with a s.c. osmotic minipump (Alzet model 1002, Alza, Vacaville, CA, USA) filled with either Ang II (Sigma-Aldrich, St Louis, MO, USA) or $\mathrm{NaCl}$ (sham-treated mice) for 14 days. The average Ang II infusion rate was $2 \mu \mathrm{g} \mathrm{kg}^{-1} \mathrm{~min}^{-1}$. To determine the effects of GJ on Ang II-induced hypertension, some animals were treated concomitantly with a s.c. implanted osmotic minipump containing GJ (1 or $3 \mu \mathrm{g} \mathrm{kg}^{-1} \mathrm{~min}^{-1}$ ) for 14 days. Systolic BPs were measured by tail cuff plethysmography with the aid of a computerized system (BP2000 Blood Pressure Analysis System, Visitech Systems, Apex, NC, USA).

\section{Preparation of aortic rings and tension measurement}

All animal procedures were conducted in accordance with the guidelines issued by the Pusan National University Animal Care and Use Committee. Mice (20-25 g) were anesthetized with sodium pentobarbital $\left(50 \mathrm{mg} \mathrm{kg}^{-1}\right.$, i.p.) and thoracic aortas were rapidly removed. Aortic rings $(2-3 \mathrm{~mm}$ thick) were suspended in 10 $\mathrm{ml}$ organ chambers filled with Krebs' solution $\left(37^{\circ} \mathrm{C}\right)$ at a resting tension of $2 \mathrm{~g}$. After aortic rings have been allowed to equilibrate for $90 \mathrm{~min}$, sustained and stable contraction was induced by treating them with phenylephrine $\left(10^{-5} \mathrm{M}\right)$. Changes in isometric tension were recorded using a force-displacement transducer (Grass FT 0.3, Quincy, MA, USA) connected to a Power Lab system 400 (ML 118, PowerLab, AD Instruments, Medford, MA, USA).

The vasodilatory potency of GJ was studied by cumulatively adding GJ at concentrations of $3 \times 10^{-5}-10^{-3} \mathrm{M}$. The involvement of $\mathrm{ED}$ in GJ-induced relaxation was also examined by comparing the magnitudes of relaxation of ED-denuded and ED-intact specimens (ED was removed by gently rubbing the intimal surface with a cotton swab). Relaxations are expressed as percentages of relaxation of phenylephrine-induced tone.

\section{Measurements of NO metabolites in plasma}

Accumulations of nitrate and nitrite, the end products of NO metabolism, were used as indices of NOS activity in plasma and were measured as previously described..$^{25}$ In brief, plasma samples were deproteinized by ultrafiltration using centrifugal concentrators (Nanosep, Pall Filtron, Northborough, MA, USA) and the supernatants were reacted with Griess solution (Promega, Madison, WI, USA) for $15 \mathrm{~min}$. Sample absorbances were measured at $540 \mathrm{~nm}$ using an Emax ELISA microplate reader and SoftMax Pro Software (Bio-Tek Instruments, Winooski, VT, USA).

\section{Measurement of NO}

At the end of the study period, mice were anesthetized with chloral hydrate ( $450 \mathrm{mg} \mathrm{kg}^{-1}$, i.p.) and thoracic aortas were rapidly excised and dissected from adhering connective and adipose tissues. For fluorometric experiments, aortic rings $(3 \mathrm{~mm}$ thick) were incubated for $2 \mathrm{~h}$ in the dark in Krebs' buffer containing $10 \mu \mathrm{M}$ 4-amino-5-methylamino-2', $7^{\prime}$-difluorofluorescein diacetate (DAF-FM DA (a fluorescent NO-sensitive dye; Molecular Probes, Karlsruhe, Germany). Aortic rings were then rapidly removed, frozen at $-20^{\circ} \mathrm{C}$, sectioned at $10 \mu \mathrm{m}$ using a microtome (HM550, MICROM GmbH, Walldorf, Germany) and placed onto microscope slides without any mounting medium or coverslip. Fluorescence was detected using an Axiovert 200 fluorescence microscope (Carl Zeiss, Oberkochem, Germany). Cells were cultured in DMEM containing 5\% fetal bovine serum. After reaching subconfluency, cells were incubated in red phenol-free DMEM containing GJ and DAF-FM DA was then loaded into cells. After incubation for $5 \mathrm{~min}$ at $37^{\circ} \mathrm{C}$, cells were washed gently three times with PBS to eliminate interference. Fluorescence was detected using an Axivoert 200 fluorescence microscope and quantified using Metamorph software (Molecular Devices, Downingtown, PA, USA).

\section{Western blot analysis for eNOS and p47phox}

Equal amounts $(20 \mu \mathrm{g})$ of protein per sample were separated on $8 \%$ SDSpolyacrylamide gel electrophoresis gels and subsequently transferred to polyvinylidenefluoride membranes. After blocking with $5 \%$ skim milk, membranes were incubated with purified mouse anti-eNOS (1:1000, Santa Cruz Biotechnology, Santa Cruz, CA, USA) and purified mouse anti-phospho Ser1177 eNOS (1:1000, Santa Cruz) at $4{ }^{\circ} \mathrm{C}$ overnight. Membranes were then washed and further incubated with secondary antibody. Bands were visualized using enhanced chemiluminescence detection reagents.

To determine membrane translocation of p47phox, cells were washed with PBS and collected. After centrifugation at $1000 \mathrm{~g}$ for $5 \mathrm{~min}$, the pellets were lysed in lysis buffer ( $12.5 \mathrm{~mm}$ Tris, $2 \mathrm{~mm}$ EGTA, $25 \mathrm{~mm} \beta$-glycerophosphate, $2 \mathrm{mM} \mathrm{Na}_{3} \mathrm{VO}_{4}, 10 \mu \mathrm{M}$ PMSF, $10 \mu \mathrm{M}$ aprotinin and $0.5 \mu \mathrm{g} \mathrm{ml}^{-1}$ leupeptin) and centrifuged at $100000 \mathrm{~g}$ for $60 \mathrm{~min}$ at $4{ }^{\circ} \mathrm{C}$. The resulting pellets were resuspended with lysis buffer containing $1 \%$ Triton X-100 and used as the membrane fraction. The supernatants were used as the cytosolic fraction.

\section{Measurement of ROS}

Vascular superoxide anion production was measured using the lucigeninenhanced chemiluminescence method. Aortic ring segments were cryocut into $3 \mu \mathrm{m}$ thick sections, mounted on gelatin chromalumin coated slides, incubated for $30 \mathrm{~min}$ with $5 \mu \mathrm{M}$ dihydroethidium and washed twice with PBS. Dihydroethidium fluorescence was detected using an Axiovert 200 fluorescence microscope (Carl Zeiss).

Intracellular ROS was measured using dichloro-dihydro-fluorescein diacetate (DCFH-DA) (Molecular Probes), which reacts with ROS to form highly fluorescent dichlorofluorescein. ${ }^{26}$ VSMCs and endothelial cells grown in 12well plates were incubated with $10 \mu \mathrm{M}$ DCFH-DA for $30 \mathrm{~min}$ and washed with PBS. DCFH-DA fluorescence was detected using an Axiovert 200 fluorescence microscope (Carl Zeiss). 
ROS activity was determined using the DCFDA Cellular ROS Detection Assay Kit (Abcam, Cambridge, MA, USA) following the manufacturer's instructions.

\section{Statistics}

Results are expressed as means \pm s.e.m. The significances of differences between the groups were determined by one-way analysis of variance followed by Tukey's multiple comparison test. The analysis was conducted using Prism version 3.03 software (GraphPad Software, San Diego, CA, USA) and P-values of $<0.05$ were regarded significant.

\section{RESULTS}

Characterization of Ang II-induced hypertension

At the beginning of the experiment, mean BP values of control and Ang II $\left(2 \mu \mathrm{g} \mathrm{kg}^{-1} \mathrm{~min}^{-1}\right)$-treated mice were $92.3 \pm 6.1 \mathrm{~mm} \mathrm{Hg}$ and $90.6 \pm 1.1 \mathrm{~mm} \mathrm{Hg}$, respectively. However, whereas control BP levels remained constant throughout the 2-week experimental period, mean BP of Ang II $\left(2 \mu \mathrm{g} \mathrm{kg}^{-1} \mathrm{~min}^{-1}\right)$-treated mice started to increase at day 2 and peaked at day $10(135.7 \pm 8.4 \mathrm{~mm} \mathrm{Hg})$ and remained at a high level for the remaining 14 days (Figure 1a). However, mean heart rates in the two groups were not significantly different throughout the experimental period $\left(417 \pm 20\right.$ beats $\mathrm{min}^{-1}$ in the control group and $572 \pm 40$ beats $\mathrm{min}^{-1}$ in the Ang II $2 \mu \mathrm{g} \mathrm{kg}^{-1} \mathrm{~min}^{-1}$ group).

When plasma concentrations of NO metabolites (nitrate plus nitrite) were plotted as a function of changes in BP, plasma levels were found to decrease significantly as BP increased in Ang II-treated mice (Figure 1b), which agrees with previous reports on the inhibition of eNOS activity by Ang II. ${ }^{27,28}$ Furthermore, aortic tissues from Ang II-infused mice had low NO concentrations and high ROS levels (Figures 1c and d).
Effect of GJ on BP and vascular NO production in Ang II-treated mice

As shown in Figure 2a, concomitant treatment with GJ (1 and 3 $\mu \mathrm{g} \mathrm{kg}^{-1} \mathrm{~min}^{-1}$ ) in Ang II-treated mice significantly and dosedependently attenuated BP increases. However, no significant intergroup difference was found among heart rates $\left(446 \pm 29\right.$ beats min $^{-1}$ in the control group; $525 \pm 27$ beats $\mathrm{min}^{-1}$ and $432 \pm 57$ beats min $^{-1}$ in the GJ $1 \mu \mathrm{g} \mathrm{kg}^{-1} \mathrm{~min}^{-1}$ - and $3 \mu \mathrm{g} \mathrm{kg}^{-1} \mathrm{~min}^{-1}$-treated groups, respectively) and heart-to-body weight ratio $\left(5.6 \pm 0.3 \mathrm{mg} \mathrm{g}^{-1}\right.$ in the control group; $5.2 \pm 0.4 \mathrm{mgg}^{-1}$ and $5.1 \pm 0.5 \mathrm{mgg}^{-1}$ in the GJ 1 $\mu \mathrm{g} \mathrm{kg}^{-1} \mathrm{~min}^{-1}$ - and $3 \mu \mathrm{g} \mathrm{kg}^{-1} \mathrm{~min}^{-1}$-treated groups, respectively).

The concentrations of NO metabolites were markedly lower in the plasma of Ang II-treated mice compared with controls. Likewise, vascular NO production (as assayed using DAF-FM) was also markedly lower in Ang II-infused animals compared with controls. Furthermore, diminished NO concentrations in isolated aortas and in plasma from Ang II-treated mice were restored by the simultaneous chronic administration of GJ ( 1 or $3 \mu \mathrm{gg}^{-1} \mathrm{~min}^{-1}$ ) in Ang IIinduced hypertensive mice (Figures $2 \mathrm{~b}$ and $\mathrm{c}$ ), suggesting that GJ might attenuate BP elevation in Ang II-treated mice by increasing the bioavailability of NO.

Effect of GJ on cellular NO production and eNOS activity In line with the vascular production of NO, cellular NO production (assayed by DAF-FM) was also markedly lower in Ang II-treated endothelial cells and restored in cells pretreated with GJ in a dosedependent manner (Figure 3a).

To assess the involvement of Ang II in the regulation of eNOS activity, we studied the effects of Ang II on the levels of eNOS and a

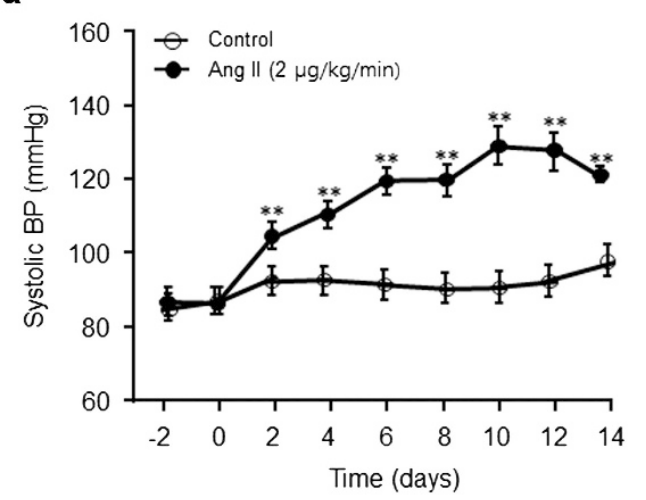

C
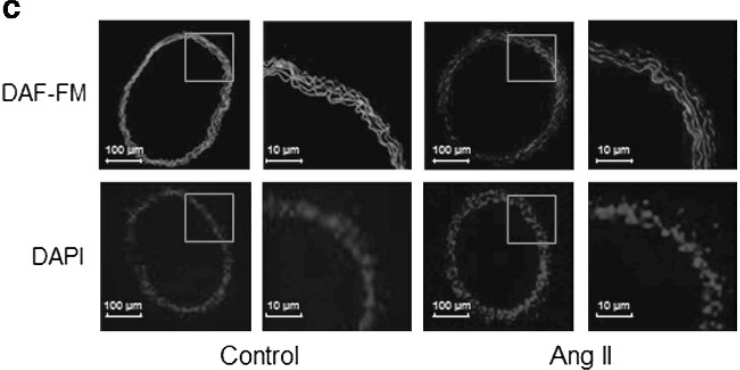

b

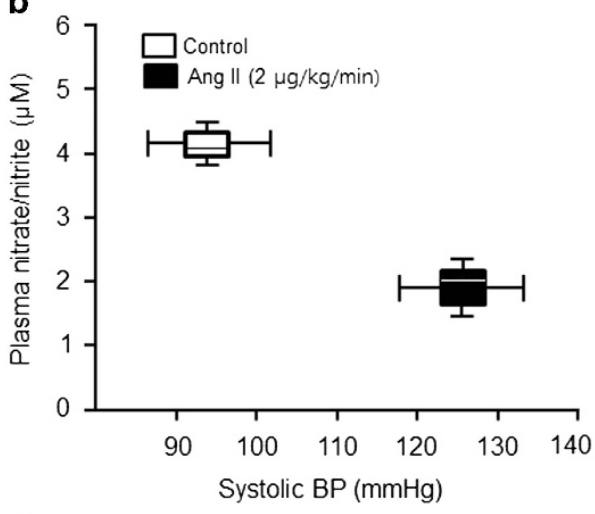

d
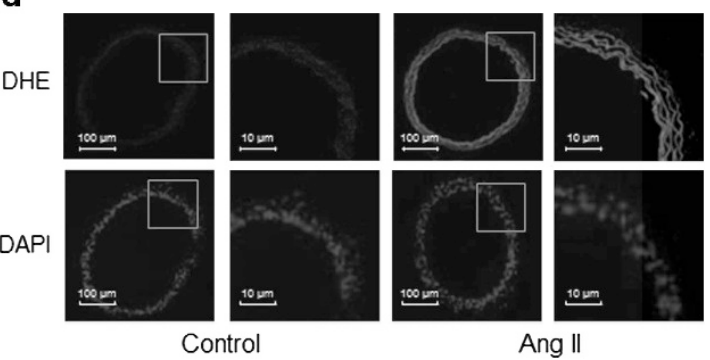

Figure 1 Effect of angiotensin II (Ang II) infusion on systolic blood pressure (BP) and on the productions of nitric oxide (NO) and reactive oxygen species (ROS). (a) Time course of systolic BP in C57BL/6 mice implanted with a s.c. osmotic minipump filled with Ang II $\left(2 \mu \mathrm{kg}^{-1} \mathrm{~min}^{-1}\right)$ for 14 days. Results are the means \pm s.e.m. of five to seven independent experiments. ${ }^{*} P<0.01$ vs. the corresponding value for controls. (b) Plasma concentrations of NO metabolites were plotted as a function of changes in BP. Results are the means \pm s.e.m. of four to seven independent experiments. Representative photographs of gomisin J-induced productions of NO (c) and ROS (d) in aortic tissues from control and Ang II-treated mice ( $n=5$ ). DAF-FM, 4-amino-5-methylamino2',7'-difluorofluorescein; DAPI, 4,6-diamidino-2-phenylindole. A full color version of this figure is available at the Hypertension Research journal online. 


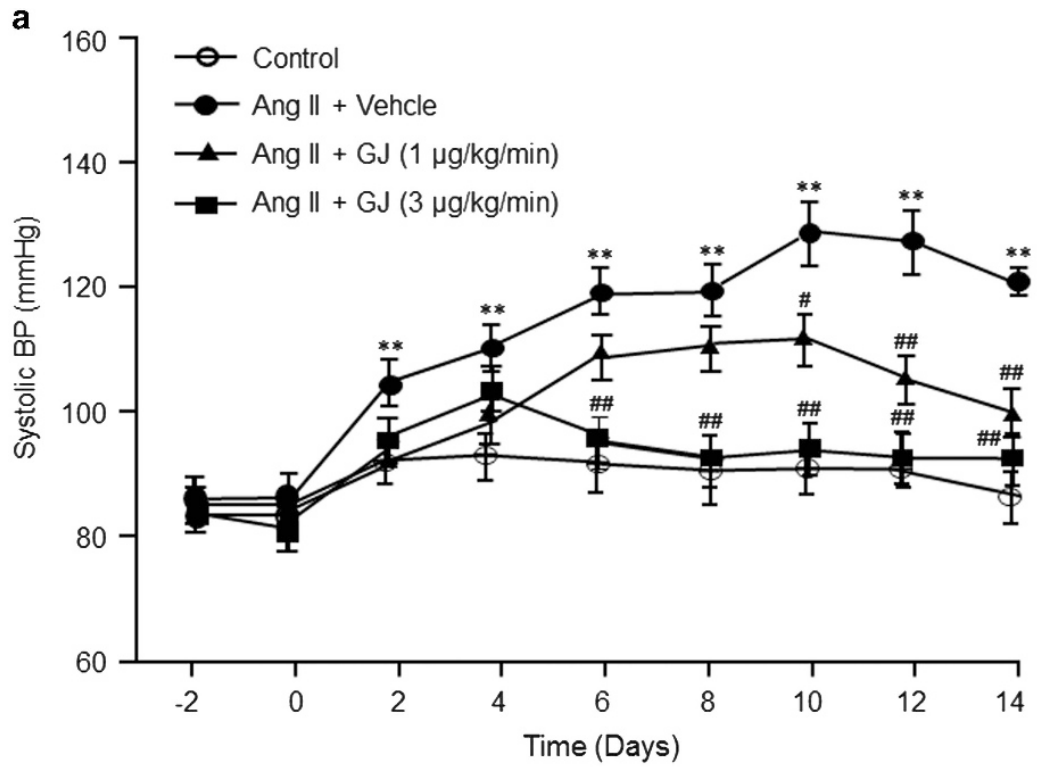

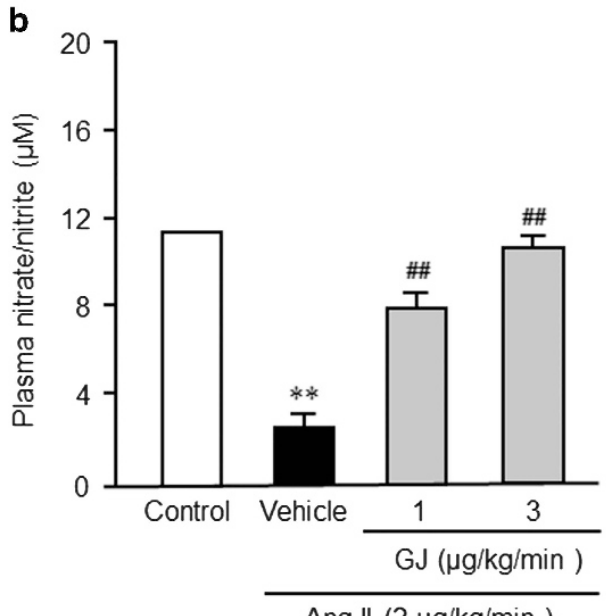

Ang II $(2 \mu \mathrm{g} / \mathrm{kg} / \mathrm{min})$ c
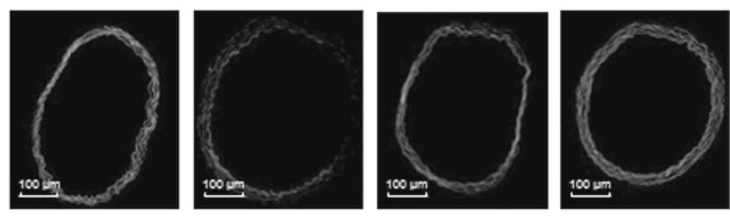

DAF-FM

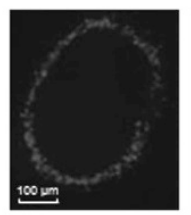

Control
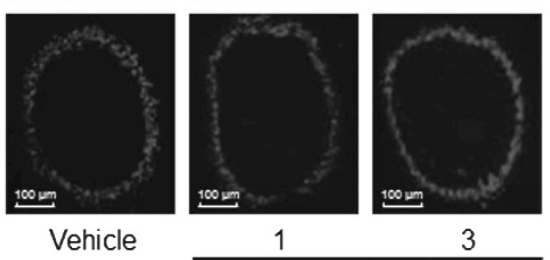

Vehicle

GJ $(\mu \mathrm{g} / \mathrm{kg} / \mathrm{min})$

DAPI

Figure 2 Effect of gomisin J (GJ) on impaired nitric oxide (NO) production in angiotensin II (Ang II)-treated mice. (a) Time course of systolic blood pressure in Ang II ( $\left.2 \mu \mathrm{g} \mathrm{kg}^{-1} \mathrm{~min}^{-1}\right)$-induced hypertensive mice treated with various concentrations of GJ ( 1 and $\left.3 \mu \mathrm{g} \mathrm{kg}^{-1} \mathrm{~min}^{-1}\right)$. Results are the means \pm s.e.m. of six to ten independent experiments. ${ }^{* *} P<0.01$ vs. the corresponding value for controls. ${ }^{\#} P<0.05 ;{ }^{\#} P<0.01$ vs. corresponding values in the vehicle group. (b) The decreased plasma concentration of NO metabolites in Ang II-treated mice was significantly prevented by the simultaneous administration of GJ (1 or $3 \mu \mathrm{g} \mathrm{kg}^{-1} \mathrm{~min}^{-1}$ ). Results are presented as the means \pm s.e.m. of four to seven independent experiments. $* * P<0.01$ vs. the control. \#\# $P<0.01$ vs. vehicle. (c) Vascular NO productions in aortic segments from control and Ang II-treated mice were measured by DAF-FM staining. Photographs are representative of five independent experiments. DAF-FM, 4-amino-5-methylamino-2',7'-difluorofluorescein; DAPI, 4,6-diamidino-2-phenylindole. A full color version of this figure is available at the Hypertension Research journal online.

phosphorylated eNOS protein expression in endothelial cells. As shown in Figure 3b, the expression level of phosphorylated eNOS at Ser ${ }^{1177}$, but not that of eNOS, was markedly lower in Ang II-treated cells and this attenuation in eNOS phosphorylation was inhibited dose-dependently by simultaneous treatment with GJ. In addition, GJ increased the expression of phosphorylated eNOS protein in control endothelial cells (Figure 3c), suggesting that GJ direct stimulated eNOS activity.

\section{Effects of GJ on Ang II-enhanced ROS production}

Ang II acts as a regulatory factor during vascular oxidation-reduction signaling by enhancing superoxide production. $^{29}$ Likewise, ROS production (measured by dihydroethidium) was significantly elevated in aortas isolated from Ang II-treated mice. Furthermore, increased
ROS production by Ang II was markedly attenuated in the aortic tissues of Ang II and GJ co-treated (Figure 4a). Likewise, when vascular cells, such as VSMCs and endothelial cells, were exposed to Ang II $(10 \mu \mathrm{M})$ for $24 \mathrm{~h}$, intracellular ROS production was markedly increased, but this increase was inhibited concentration-dependently by GJ (Figures $4 \mathrm{~b}$ and $\mathrm{c}$ ).

To determine molecular mechanism by which GJ inhibits ROS production, we investigated the role of GJ on membrane translocation of cytosolic p47phox because p47phox phosphorylation and subsequent translocation to membrane is known as an initiating mechanism to activate NADPH oxidase. In cells stimulated with Ang II, an increase in the membrane fraction of p47phox was detectable at $30 \mathrm{~min}$ and maintained high up to $60 \mathrm{~min}$, which was markedly attenuated by pretreatment with GJ (Figure 5a). These results 
a

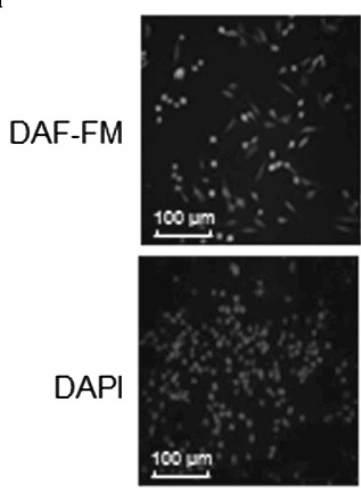

Control
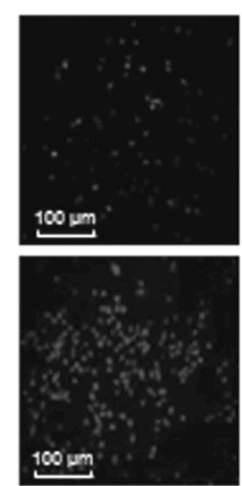

Vehicle
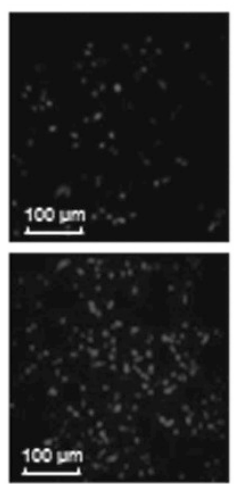

0.3
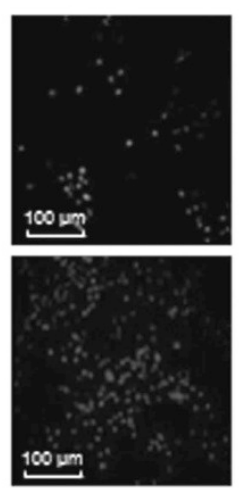

1
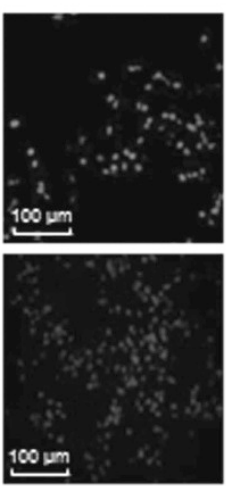

3

$G J(\mu g / m l)+$ Ang $\|(10 \mu M)$

b
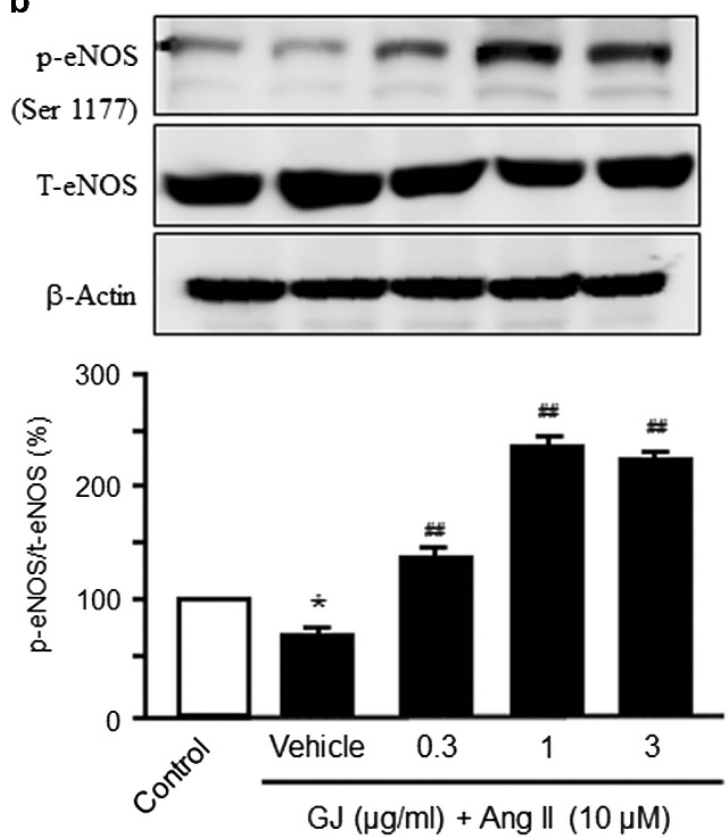

c

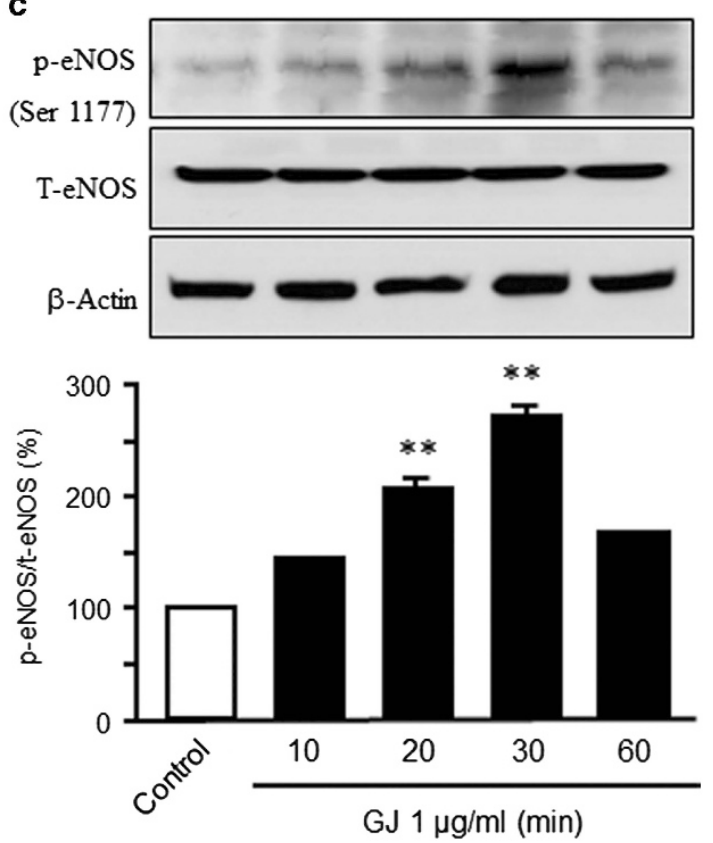

Figure 3 Effect of gomisin J (GJ) on impaired nitric oxide (NO) production in endothelial cells treated with angiotensin II (Ang II). (a) Representative photographs of the preservation of NO production by GJ in endothelial cells treated with Ang $\|(10 \mu \mathrm{m})(n=5)$. (b and $\mathbf{c})$ Representative immunoblots showing the effect of GJ on endothelial nitric oxide synthase (eNOS) phosphorylation at Ser1177 in control and Ang II-treated cells. Bars represent means \pm s.e.m. of four to six independent experiments. ${ }^{*} P<0.05 ;{ }^{*} P<0.01$ vs. the control. ${ }^{\# \#} P<0.01$ vs. vehicle. DAF-FM, 4-amino-5-methylamino-2', $7^{\prime}-$ difluorofluorescein; DAPI, 4,6-diamidino-2-phenylindole. A full color version of this figure is available at the Hypertension Research journal online.

suggested that GJ attenuated ROS production induced by Ang II via an inhibition of membrane translocation of cytosolic p47phox.

To further examine the ROS scavenging activity of GJ, we examined the effect of GJ on SIN-1-induced ROS production. As shown in Figure 5b, GJ had no effect on ROS production by SIN-1, whereas tolox dose-dependently decreased SIN-1-induced ROS production. These findings suggest that GJ inhibits ROS generation by Ang II, but that it has no direct scavenging effect.

Comparison of the potencies on the vasodilatory and antihypertensive effects of GJ and GA

As shown in Figures $6 a$ and b, the vasorelaxant effect of GJ (0.1$30 \mu \mathrm{M})$ was more marked than that of GA $(0.1-30 \mu \mathrm{M})$ in phenylephrine $(10 \mu \mathrm{M})$-precontracted aortic rings. Half-maximal effective dose values for the vasodilatory effects of GJ and GA were $99 \pm 12 \mu \mathrm{M}$ and $284 \pm 31 \mu \mathrm{M}$, respectively. The most potent inhibitory effects of GJ on BP was also demonstrated in time course study of Ang II (2 $\left.\mu \mathrm{g} \mathrm{kg}^{-1} \mathrm{~min}^{-1}\right)$-induced hypertensive mice treated with same concentrations $\left(3 \mu \mathrm{g} \mathrm{kg}^{-1} \mathrm{~min}^{-1}\right)$ of GA, GJ and losartan (Figure 6c).

\section{DISCUSSION}

The present study shows that the increase in arterial BP shown by mice infused s.c. with Ang II is markedly attenuated by the chronic administration of GJ. Furthermore, the beneficial effects of GJ on Ang II-induced hypertension were found to be partly associated with preservation of the bioavailability of $\mathrm{NO}$ in the vasculature. In addition, in the present study, GJ treatment was started at the prehypertensive stage, and thus, our results suggest that GJ has a 


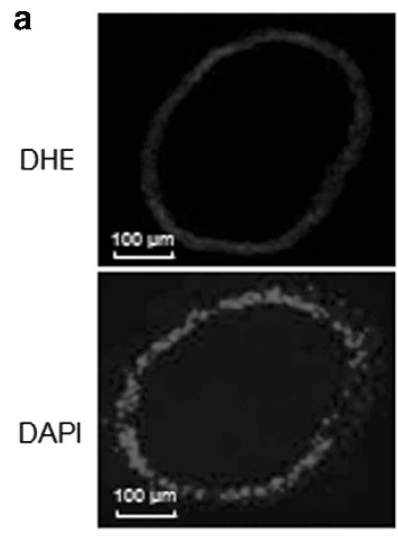

Control

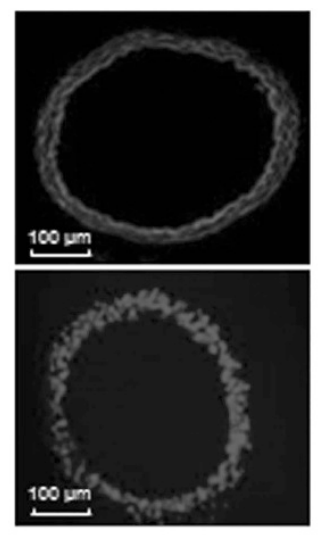

Vehicle
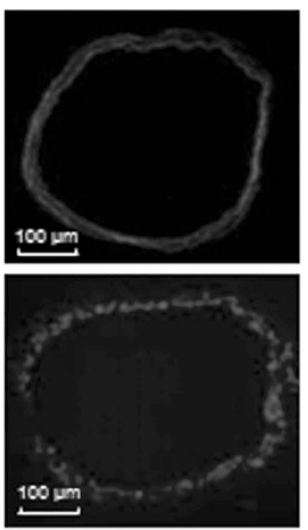

1
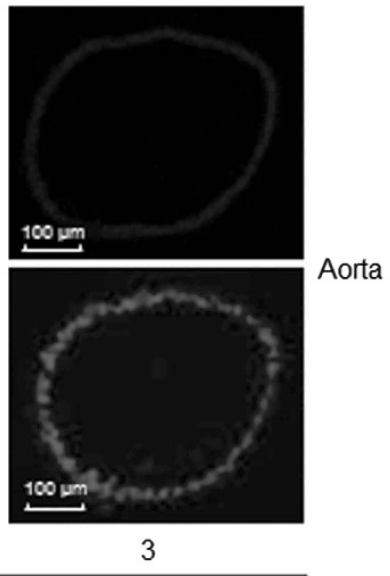

3

GJ $(\mu \mathrm{g} / \mathrm{kg} / \mathrm{min})+$ Ang $\|(2 \mu \mathrm{g} / \mathrm{kg} / \mathrm{min})$

b
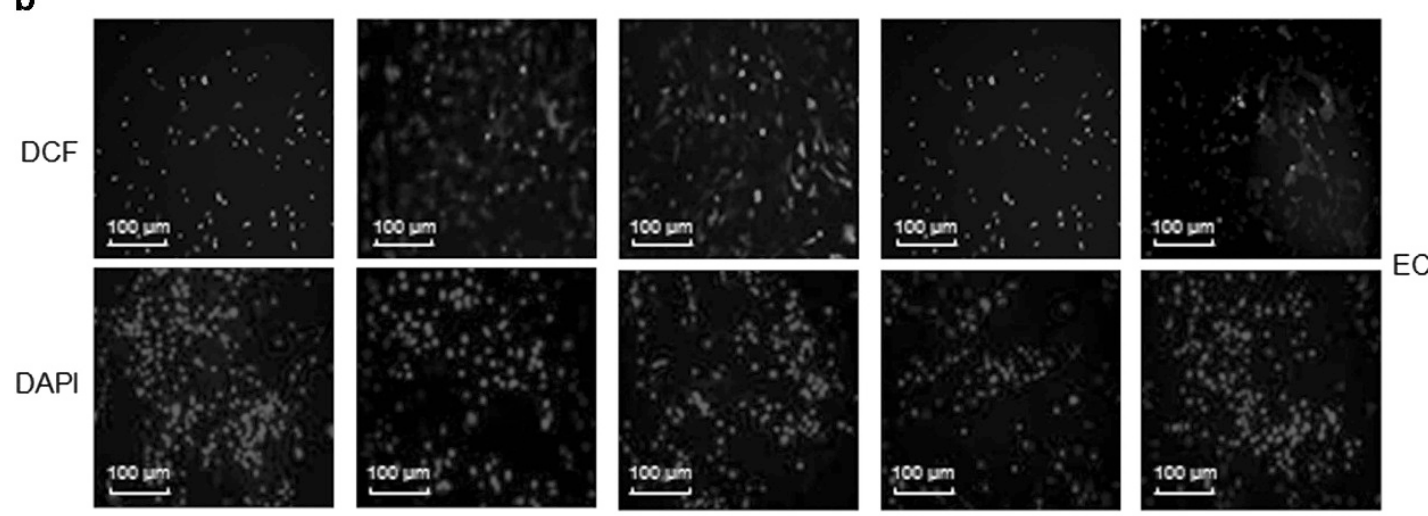

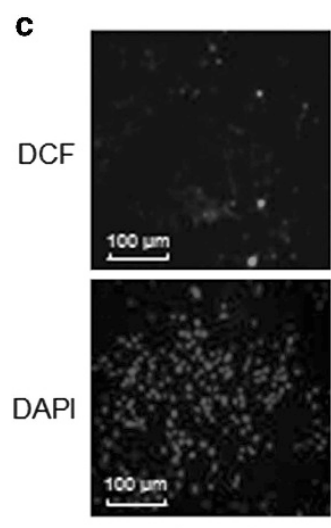

Control
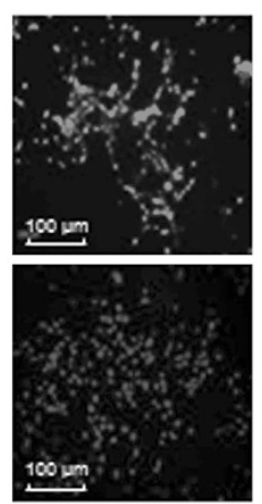

Vehicle
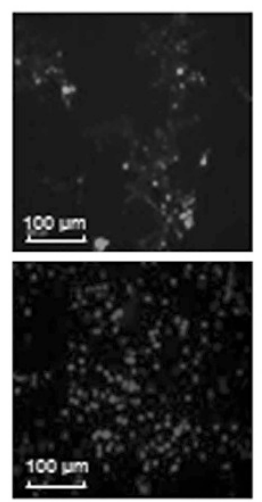

0.3
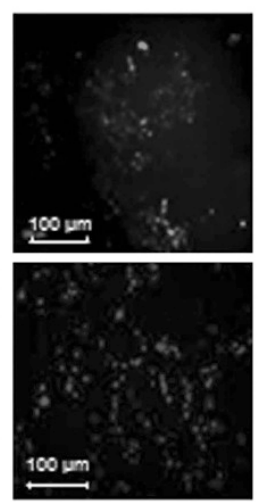

1
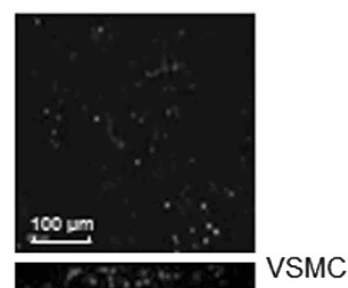

$\mathrm{GJ}(\mu \mathrm{g} / \mathrm{ml})+$ Ang $\|(10 \mu \mathrm{M})$

Figure 4 Effects of gomisin J (GJ) on angiotensin II (Ang II)-enhanced reactive oxygen species (ROS) production. (a) Representative photographs of ROS production as measured by dihydroethidium in aortic tissues from control and Ang II-treated mice with or without simultaneous GJ treatment ( $n=5$ ). (b) Endothelial cells (ECs) and vascular smooth muscle cells (VSMCs) were exposed to Ang II (10 $\mu \mathrm{m})$ for $1 \mathrm{~h}$ in the presence or absence of GJ and then ROS production in cells was determined by measuring DCF fluorescence. Photographs are representative of five to six experiments. DAPI, 4,6-diamidino-2phenylindole; DCF, dichlorofluorescein; DHE, dihydroethidium. A full color version of this figure is available at the Hypertension Research journal online.

prophylactic effect against the development of hypertension induced by Ang II.

Despite the large number of antihypertensive drugs developed and the progress made regarding the efficacies and tolerabilities of these agents, it is acknowledged that $<25 \%$ of treated individuals achieve target BP levels. ${ }^{30}$ The current trend toward lower BP goals suggests that more effective and better tolerated antihypertensive therapies are needed, and in this context, natural products are an excellent potential source for candidates. Indeed, in our previous studies, hexane extracts of SC induced vasorelaxation in isolated rat thoracic aorta in an EDdependent and independent manner. ${ }^{31}$ Furthermore, the relaxant effect of SC extracts on ED-intact aortas was more prominent than 
a

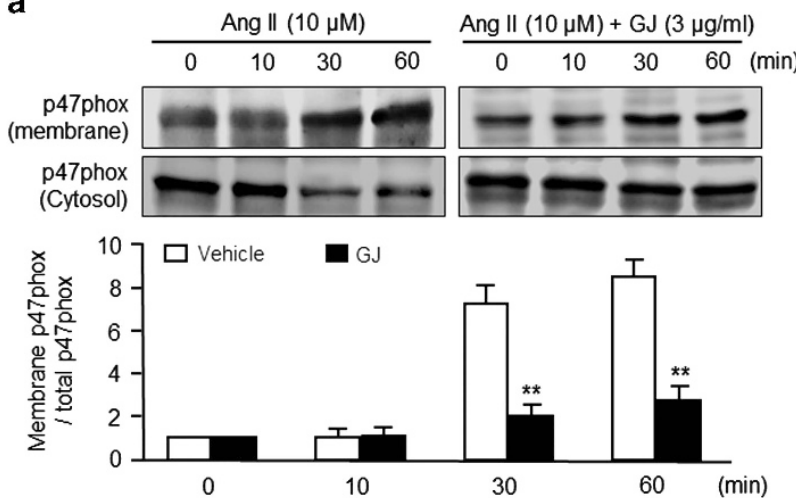

b

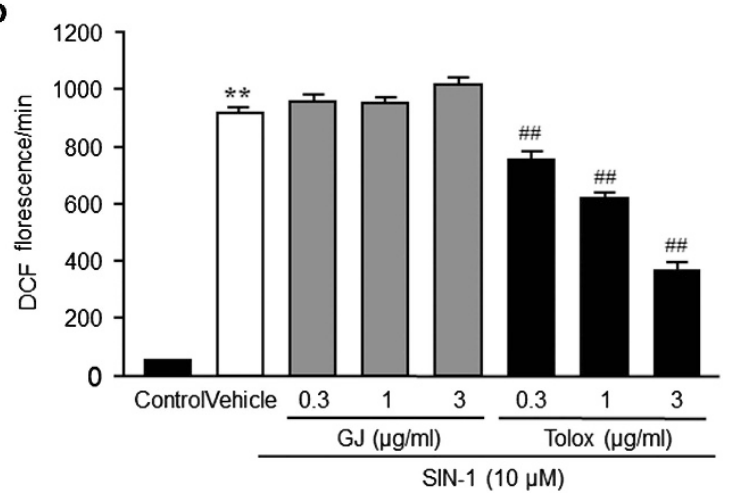

Figure 5 Effects of gomisin J (GJ) on membrane translocation of cytosolic p47phox in endothelial cells treated with angiotensin II (Ang II). (a) Cells were exposed to Ang II $(10 \mu \mathrm{m})$ for the indicated time in the presence or absence of GJ. Representative immunoblot of p47phox. Data were expressed as ratio of membrane p47phox/total p47phox (cytosolic p47phox+membrane p47phox) and represented as means \pm s.e.m. of five to seven independent experiments. ${ }^{* *} P<0.01$ vs. vehicle. (b) Cells were treated with $\mathrm{SIN}-1$ $(10 \mu \mathrm{m})$ for $30 \mathrm{~min}$ and then stimulated with Tolox and GJ $\left(0.3-3 \mu \mathrm{g} \mathrm{ml}{ }^{-1}\right)$. Trolox was used as a positive control. Reactive oxygen species activity within the cell was determined using DCF fluorescence. Results are the means $\pm \mathrm{s}$. e.m. of five independent experiments. ${ }^{* *} P<0.01$ vs. the control. ${ }^{\# \# P<0.01}$ vs. vehicle. DCF, dichlorofluorescein.

that on ED-denuded aortas. Accordingly, it was suggested that SC extracts might regulate $\mathrm{BP}$ via the $\mathrm{ED}$-dependent $\mathrm{NO}$ pathway.

It has been shown that the vascular $\mathrm{ED}$ of hypertensive patients produces less $\mathrm{NO}^{32}$ and it has been suggested compounds that enhance endothelial function through the NO pathway might have potential in the prevention and treatment of hypertension. ${ }^{33-35}$ Therefore, the present study was designed to investigate the preventive role of GJ on the development of hypertension in mice treated with Ang II. In line with previous studies on the topic, ${ }^{23,36,37}$ we found an increase in arterial BP was associated with a decrease in $\mathrm{NO}$ metabolite levels in plasma and aortas of mice infused s.c. with Ang II.

The decreased levels of $\mathrm{NO}$ in vasculature could result from a reduction in NO synthesis via the inhibition of eNOS activity or enhanced NO inactivation due to greater ROS production in the vasculature. In the present study, ROS production in aortas was also significantly elevated in mice treated with Ang II. Thus, dysfunctional $\mathrm{ED}$, characterized by less NO production and increased ROS production, appeared to lead to an increase in arterial BP in Ang II-infused mice via a decrease in NO bioavailability. It would appear that this decline in NO bioavailability could have been caused by alterations in cellular signaling involved in eNOS activation or by the enhanced degradation of NO by ROS. ${ }^{38}$

The present study shows that the chronic administration of Ang II to mice caused an increase in arterial BP and a decrease in the plasma concentrations of NO metabolites and that these were prevented by the continuous infusion of GJ. In our previous study, ${ }^{23}$ acute exposure of rat thoracic aorta to GJ caused vasorelaxation in both ED-intact and ED-denuded vasculature, although the vasorelaxant effects of GJ in ED-intact aorta were more prominent than those in ED-denuded vasculature. In addition, GJ induced an increase in NO production in the endothelial layer of rat thoracic aortas and in human coronary artery endothelial cells, which suggests that the vasorelaxation induced by GJ is mainly mediated by an NO-dependent pathway. On the basis of these previous data, the effect of GJ on NO bioavailability in Ang II-infused mice might be due to its protective effect on impaired NO synthesis or on increased NO inactivation by ROS.

To determine the role of GJ in NO synthesis, we investigated the effect of GJ on the regulation of eNOS activity. It was found that GJ attenuated the decrease in phosphorylated eNOS (Ser ${ }^{1177}$ ) expression and restored diminished plasma nitrate/nitrite levels. In our previous study, GA rapidly stimulated NO production and eNOS activation by enhancing eNOS phosphorylation without markedly affecting total eNOS expression. ${ }^{23}$ Likewise, in the present study, the level of eNOS expression in endothelial cells treated with Ang II was neither decreased compared with that in control nor affected by GJ treatment. In line with our previous study, ${ }^{23}$ the present study shows that the diminished level of phosphorylated eNOS in Ang II-treated endothelial cells is markedly preserved by GJ, indicates that GJ prevents Ang II-induced impairment of eNOS phosphorylation without affecting eNOS expression. However, further experiments are necessary to determine the effect of GJ on cross-talk between Ang II and eNOS.

The overproduction of ROS in blood vessel walls inhibits the synthesis of prostacyclin, ${ }^{39,40}$ and together with the chemical inactivation of NO, probably impairs ED-dependent relaxation and favors an increase in arterial tone. ${ }^{40,41}$ Many of the consequences of Ang II exposure, such as hypertension and vascular remodeling, are reportedly related to ROS formation due to the activation of NADPH oxidases. ${ }^{42,43}$ Sachse and $\mathrm{Wolf}^{44}$ provided evidence that Ang II stimulates the intracellular formation of superoxide by upregulating subunits of membrane-bound $\mathrm{NAD}(\mathrm{P}) \mathrm{H}$ oxidase and by facilitating the assembly of these subunits. In endothelial cells, Ang II activates mainly the Nox2 (gp91phox) and Nox4 subunits and the genetic disruption of Nox 2 prevented the endothelial dysfunction observed in a high-renin model of hypertension. ${ }^{45}$ Therefore, we assessed ROS production in the vasculature isolated from Ang II-infused mice, as well as in vascular cells (endothelial cells and VSMCs). The present study demonstrates that ROS production in the aortic tissues of Ang II-treated mice and in vascular cells treated with Ang II was markedly increased. These findings suggest that the hypertension caused by Ang II is mediated in part by reduced NO bioavailability caused by increased ROS production in the vasculature.

However, the increased ROS production in aortas isolated from Ang II-treated mice was markedly attenuated in Ang II-treated mice cotreated with GJ. In addition, in agreement with previous studies, in which Ang II enhanced ROS production in endothelial cells and VSMCs, ${ }^{46,47}$ this study also shows that Ang II increased ROS in vascular cells. Moreover, in line with the results of our in vivo study, Ang II-induced ROS production in cultured vascular cells was also markedly attenuated by GJ pretreatment. Recently, it was reported that 


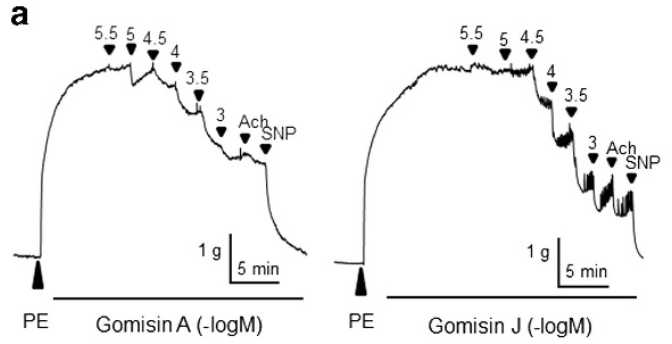

b

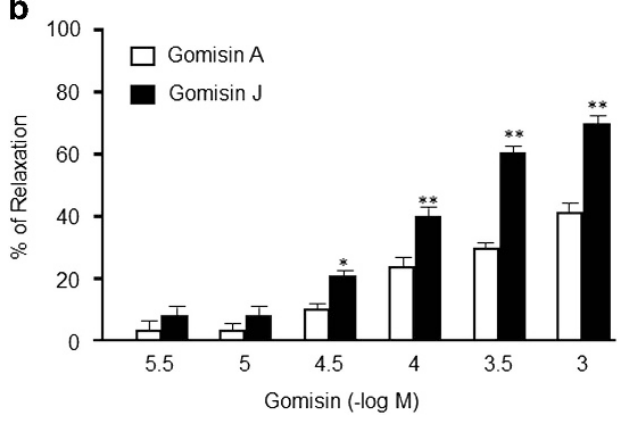

c

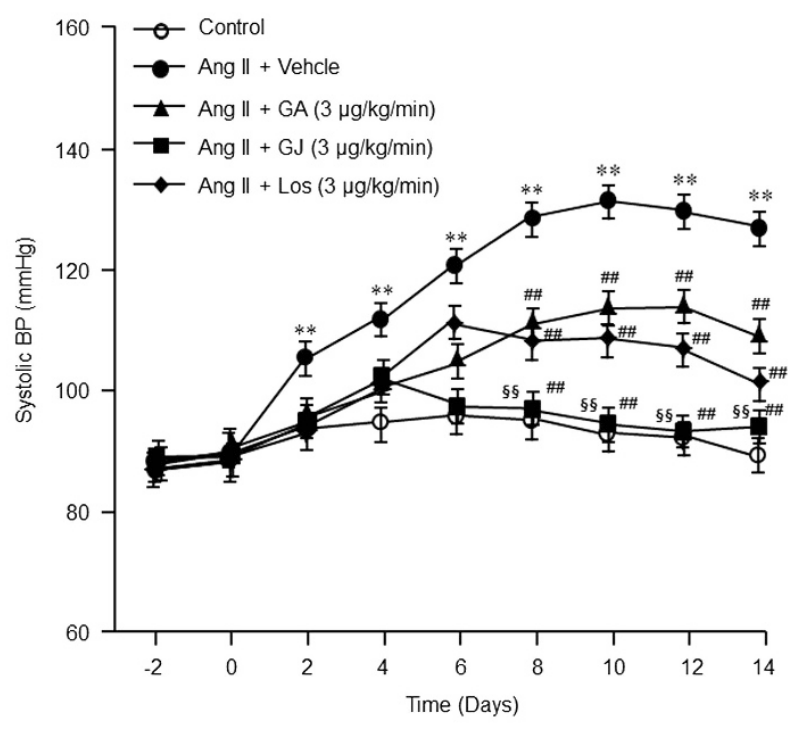

Figure 6 Comparison of the vasodilatory and antihypertensive potencies of gomisin J (GJ) and gomisin A (GA). (a and b) Representative tracings showing the vasorelaxing effects of $\mathrm{GJ}\left(3 \times 10^{-5}-10^{-3} \mathrm{M}\right)$ and $\mathrm{GA}\left(3 \times 10^{-5}-10^{-3} \mathrm{M}\right)$ on phenylephrine $(10 \mu \mathrm{m})$-precontracted aortic rings. Bars represent the means \pm s.e. $\mathrm{m}$. of four to six independent experiments. ${ }^{*} P<0.05 ;{ }^{*} P<0.01$ vs. corresponding values in the GA group. (c) Time course of systolic blood pressure in angiotensin II (Ang II) $\left(2 \mu \mathrm{g} \mathrm{kg}^{-1} \mathrm{~min}^{-1}\right)$-induced hypertensive mice treated with same concentrations $\left(3 \mu \mathrm{g} \mathrm{kg}^{-1} \mathrm{~min}^{-1}\right)$ of GA, GJ or losartan. Results are the means \pm s.e.m. of six to ten independent experiments. ${ }^{* *} P<0.01$ vs. corresponding control values. ${ }^{\# \#} P<0.01$ vs. corresponding values in the vehicle group. ${ }^{\S \S} P<0.01$ vs. corresponding values in the GA group.

treatment with antioxidants blunts the increase in BP caused by Ang II. ${ }^{11,48}$ Likewise, the results of the present study suggest that the antioxidative property-related protection afforded against ROSmediated degradation of $\mathrm{NO}$ in vasculature might be involved in, at least in part, the antihypertensive effect of GJ. However, in our in vitro study, which was conducted to determine the mechanism responsible for the antioxidant activity of GJ, ROS production induced by chemical reaction was not inhibited by GJ, which suggested an antioxidant effect via the inhibition of a ROS-generating enzyme. Evidently, more experimentation is needed to determine the nature of cross-talk between GJ and enzymes involved in ROS generation.

In conclusion, the chronic administration of GJ had an antihypertensive effect in Ang II-induced hypertensive mice. Moreover, the beneficial effects of GJ on NO bioavailability, which were mediated by the preservation of vascular NO, appeared to be related to its antihypertensive activity. On the basis of these results, we suggest that GJ attenuated increases in arterial BP by preserving vascular NO bioavailability, by inhibiting ROS production and by preventing the impairment of eNOS function in the vasculature of Ang II-induced hypertensive mice. Furthermore, the antihypertensive effects of GJ were greater than those of GA or losartan, suggesting that GJ has been regarded as a promising antihypertensive agent.

\section{CONFLICT OF INTEREST}

The authors declare no conflict of interest.

\section{ACKNOWLEDGEMENTS}

This study was supported by the Bio-industry Technology Development Program, Ministry for Food, Agriculture, Forestry and Fisheries, Republic of Korea (311054-03-1-HD120).
1 Nguelefack TB, Dongmo AB, Dimo T, Kamanyi A. Phytopharmacology of some medicinal plants used in Cameroonian traditional medicine to handle cardiovascular diseases. in Anna Capasso (ed.), Recent Developments in Medicinal Plant Research. 2007; pp. 147-167.

2 John WO, Marcos T. Sympathetic signatures of cardiovascular disease: a blueprint for development of targeted sympathetic ablation therapies. Hypertension 2012; 59 545-547.

3 Olga T, Sergey S. The influence of oxonate-induced hyperuricemia and allopurinol on behavioral reactions of random-bred mice. J Basic Clin Physiol Pharmacol 2012; 23: 147-151.

4 Davignon J, Ganz P. Role of endothelial dysfunction in atherosclerosis. Circulation 2004; 109: III27-III32.

5 Law MR, Morris JK, Wald NJ. Use of blood pressure lowering drugs in the prevention of cardiovascular disease: meta-analysis of 147 randomised trials in the context of expectations from prospective epidemiological studies. BMJ 2009; 338: b1665.

6 Fulton D, Gratton JP, Sessa WC. Post-translational control of endothelial nitric oxide synthase: why isn't calcium/calmodulin enough? J Pharmacol Exp Ther 2001; 299. 818-824

7 Venema RC. Post-translational mechanisms of endothelial nitric oxide synthase regulation by bradykinin. Int Immunopharmacol 2002; 2: 1755-1762.

8 Schulz E, Jansen T, Wenzel P, Daiber A, Munzel T. Nitric oxide, tetrahydrobiopterin, oxidative stress, and endothelial dysfunction in hypertension. Antioxid Redox Signal 2008; 10: 1115-1126.

9 Watanabe T, Barker TA, Berk BC. Angiotensin II and the endothelium: diverse signals and effects. Hypertension 2005; 45: 163-169.

10 Nakashima H, Suzuki H, Ohtsu H, Chao JY, Utsunomiya H, Frank GD, Eguchi S. Angiotensin II regulates vascular and endothelial dysfunction: recent topics of angiotensin II type-1 receptor signaling in the vasculature. Curr Vasc Pharmacol 2006; 4: 67-78.

11 Virdis A, Duranti E, Taddei S. Oxidative stress and vascular damage in hypertension: role of angiotensin II. Int J Hypertens 2011; 2011: 916310.

12 Konior A, Schramm A, Czesnikiewicz-Guzik M, Guzik TJ. NADPH oxidases in vascular pathology. Antioxid Redox Signal 2013; 20: 2794-2814.

13 Garrido AM, Griendling KK. NADPH oxidases and angiotensin II receptor signaling. Mol Cell Endocrinol 2009; 302: 148-158.

14 Murdoch CE, Alom-Ruiz SP, Wang M, Zhang M, Walker S, Yu B, Brewer A, Shah AM. Role of endothelial Nox2 NADPH oxidase in angiotensin Il-induced hypertension and vasomotor dysfunction. Basic Res Cardiol 2011; 106: 527-538.

15 Nishida M, Ishikawa T, Saiki S, Sunggip C, Aritomi S, Harada E, Kuwahara K, Hirano K, Mori Y, Kim-Mitsuyama S. Voltage-dependent $\mathrm{N}$-type $\mathrm{Ca} 2+$ channels in endothelial cells contribute to oxidative stress-related endothelial dysfunction induced by angiotensin II in mice. Biochem Biophys Res Commun 2013; 434: 210-216. 
16 Choi YW, Takamatsu S, Khan SI, Srinivas PV, Ferreira D, Zhao J, Khan IA. Schisandrene, a dibenzocyclooctadiene lignan from Schisandra chinensis: structureantioxidant activity relationships of dibenzocyclooctadiene lignans. J Nat Prod 2006; 69: 356-359.

$17 \mathrm{Lu}$ Y, Chen DF. Analysis of Schisandra chinensis and Schisandra sphenanthera. J Chromatogr A 2009; 1216: 1980-1990.

18 Ma D, Shan A, Chen Z, Du J, Song K, Li J, Xu Q. Effect of Ligustrum lucidum and Schisandra chinensis on the egg production, antioxidant status and immunity of laying hens during heat stress. Arch Anim Nutr 2005; 59: 439-447.

19 Smejkal K, Slapetova T, Krmencik P, Kubinova R, Suchy P, Dall'Acqua S, Innocenti G, Vanco J, Kalvarova K, Dvorska M, Slanina J, Kramarova E, Muselik J, Zemlicka M. Evaluation of the antiradical activity of Schisandra chinensis lignans using different experimental models. Molecules 2010; 15: 1223-1231.

20 Huang T, Shen P, Shen Y. Preparative separation and purification of deoxyschisandrin and gamma-schisandrin from Schisandra chinensis (Turcz.) Baill by high-speed counter-current chromatography. J Chromatogr A 2005; 1066: 239-242.

21 Yoshikawa A, Saito Y, Maruyama K. Lignan compounds and 4,4'-dihydroxybiphenyl protect $\mathrm{C} 2 \mathrm{C} 12$ cells against damage from oxidative stress. Biochem Biophys Res Commun 2006; 344: 394-399.

22 Oh SY, Kim YH, Bae DS, Um BH, Pan CH, Kim CY, Lee HJ, Lee JK. Anti-inflammatory effects of gomisin N, gomisin J, and schisandrin $\mathrm{C}$ isolated from the fruit of Schisandra chinensis. Biosci Biotechnol Biochem 2010; 74: 285-291.

23 Park JY, Choi YW, Yun JW, Bae JU, Seo KW, Lee SJ, Park SY, Kim CD. Gomisin J from Schisandra chinensis induces vascular relaxation via activation of endothelial nitric oxide synthase. Vascul Pharmacol 2012; 57: 124-130.

24 Park JY, Lee SJ, Yun MR, Seo KW, Bae SS, Park JW, Lee YJ, Shin WJ, Choi YW, Kim CD. Gomisin A from Schisandra chinensis induces endothelium-dependent and direct relaxation in rat thoracic aorta. Planta Med 2007; 73: 1537-1542.

25 Kukongviriyapan V, Somparn N, Senggunprai L, Prawan A, Kukongviriyapan U, Jetsrisuparb A. Endothelial dysfunction and oxidant status in pediatric patients with hemoglobin E-beta thalassemia. Pediatr Cardiol 2008; 29: 130-135.

26 Amer J, Goldfarb A, Fibach E. Flow cytometric measurement of reactive oxygen species production by normal and thalassaemic red blood cells. Eur J Haematol 2003; 70: 84-90.

27 Lin LY, Lin CY, Su TC, Liau CS. Angiotensin II-induced apoptosis in human endothelial cells is inhibited by adiponectin through restoration of the association between endothelial nitric oxide synthase and heat shock protein 90. Febs Lett 2004; 574: $106-110$.

$28 \mathrm{Xu} \mathrm{L}$, Liu Y. Administration of telmisartan reduced systolic blood pressure and oxidative stress probably through the activation of PI3K/Akt/eNOS pathway and no release in spontaneously hypertensive rats. Physiol Res 2013; 62: 351-359.

29 Massey KJ, Hong NJ, Garvin JL. Angiotensin II stimulates superoxide production in the thick ascending limb by activating NOX4. Am J Physiol Cell Physiol 2012; 303: C781-C789.

30 Evans RG, Majid DS, Eppel GA. Mechanisms mediating pressure natriuresis: what we know and what we need to find out. Clin Exp Pharmacol Physiol 2005; 32: 400-409.

31 Park JY, Shin HK, Choi YW, Lee YJ, Bae SS, Han J, Kim CD. Gomisin A induces Ca2+dependent activation of eNOS in human coronary artery endothelial cells. J Ethnopharmacol 2009; 125: 291-296.
32 Razny U, Kiec-Wilk B, Wator L, Polus A, Dyduch G, Solnica B, Malecki M, Tomaszewska $\mathrm{R}$, Cooke JP, Dembinska-Kiec A. Increased nitric oxide availability attenuates high fat diet metabolic alterations and gene expression associated with insulin resistance. Cardiovasc Diabetol 2011; 10: 68

33 Landmesser U, Drexler H. Chronic heart failure: an overview of conventional treatment versus novel approaches. Nat Clin Pract Cardiovasc Med 2005; 2: 628-638.

34 Young Park J, Wook Yun J, Whan Choi Y, Ung Bae J, Won Seo K, Jin Lee S, Youn Park S, Whan Hong K, Kim CD. Antihypertensive effect of gomisin A from Schisandra chinensis on angiotensin II-induced hypertension via preservation of nitric oxide bioavailability. Hypertens Res 2012; 35: 928-934.

35 Kwak JH, Kim M, Lee E, Lee SH, Ahn CW, Lee JH. Effects of black soy peptide supplementation on blood pressure and oxidative stress: a randomized controlled trial. Hypertens Res 2013; 36: 1060-1066.

36 Chen X, Qiu Z, Yang S, Ding D, Chen F, Zhou Y, Wang M, Lin J, Yu X, Zhou Z, Liao Y. Effectiveness and safety of a therapeutic vaccine against angiotensin II receptor type 1 in hypertensive animals. Hypertension 2013; 61: 408-416.

37 Zhou YB, Sun HJ, Chen D, Liu TY, Han Y, Wang JJ, Tang CS, Kang YM, Zhu GQ. Intermedin in paraventricular nucleus attenuates sympathetic activity and blood pressure via nitric oxide in hypertensive rats. Hypertension 2013; 63: 330-337.

38 Cai H. Harrison DG. Endothelial dysfunction in cardiovascular diseases: the role of oxidant stress. Circ Res 2000; 87: 840-844.

39 Katusic ZS. Superoxide anion and endothelial regulation of arterial tone. Free Radic Biol Med 1996; 20: 443-448.

40 Katusic ZS, Vanhoutte PM. Effects of SIN-1 on isolated canine basilar arteries. J Cardiovasc Pharmacol 1989; 14(Suppl 11)S72-S75.

41 Feletou M, Vanhoutte PM. Endothelium-dependent hyperpolarization of canine coronary smooth muscle. Br J Pharmacol 1988; 93: 515-524.

42 Zhao W, Zhao D, Yan R, Sun Y. Cardiac oxidative stress and remodeling following infarction: role of NADPH oxidase. Cardiovasc Pathol 2009; 18: 156-166.

43 Ikeda Y, Aihara K, Yoshida S, Sato T, Yagi S, Iwase T, Sumitomo Y, Ise T, Ishikawa K, Azuma H, Akaike M, Kato S, Matsumoto T. Androgen-androgen receptor system protects against angiotensin II-induced vascular remodeling. Endocrinology 2009; 150: 2857-2864.

44 Sachse A, Wolf G. Angiotensin II-induced reactive oxygen species and the kidney. J Am Soc Nephrol 2007; 18: 2439-2446.

45 Jung O, Schreiber JG, Geiger H, Pedrazzini T, Busse R, Brandes RP. gp91phoxcontaining NADPH oxidase mediates endothelial dysfunction in renovascular hypertension. Circulation 2004; 109: 1795-1801.

46 Zhang $H$, Schmeisser A, Garlichs CD, Plotze K, Damme U, Mugge A, Daniel WG. Angiotensin II-induced superoxide anion generation in human vascular endothelial cells: role of membrane-bound NADH-/NADPH-oxidases. Cardiovasc Res 1999; 44: 215-222.

47 Lavigne MC, Malech HL, Holland SM, Leto TL. Genetic demonstration of p47phoxdependent superoxide anion production in murine vascular smooth muscle cells. Circulation 2001; 104: 79-84.

48 Nakmareong S, Kukongviriyapan U, Pakdeechote P, Donpunha W, Kukongviriyapan V, Kongyingyoes B, Sompamit K, Phisalaphong C. Antioxidant and vascular protective effects of curcumin and tetrahydrocurcumin in rats with L-NAME-induced hypertension. Naunyn Schmiedebergs Arch Pharmacol 2011; 383: 519-529. 